\title{
O DIREITO ADMINISTRATIVO NA OBRA DO PROFESSOR. MANOEL DE OLIVEIRA FRANCO SOBRINHO
}

\author{
PEDRO AUGUSTO MENNA BARRETO MONCLARO \\ Docente Livre de Direito Administrativo
}

Em 1939, o ilustre saudoso professor Tito Prates da Fonseca, na primeira edição do seu "Direito Administrativo", em substancioso prefácio explicativo exaltava a preocupação de alguns juristas nossos pelo estudo, investigação e pesquisa dos problemas essenciais à administração pública. De fato, por muito tempo, o "Direito Adminis. trativo" não encontrou no Brasil o interêsse que era de esperar principalmente num país em formação política de organização constitucional federativa. No Império houve nomes respeitáveis: Uruguaí, Ribas, Cabral e Furtado de Mendonça. De 1889 até 1930 vários no. mes pontificaram: Amaro Cavalcanti, Viveiros de Castro, Alcides Cruz e Oliveira Santos. De 1930 para cá iniciou-se a grande fase com Temístocles Brandão Cavalcanti, José Matos de Vasconcelos, Rui Cirne Lima e J. Guimarães Menegale, como tratadistas, inclusive Tito Prates, com trabalhos de caracter científico até agora compulsados.

* * *

Também inúmeras monografias apareceram dando expansão ao pensamento brasileiro sôbre tão importante disciplina, nestas três últimas décadas. São ainda atuais os trabalhos de Mário Masagão, Rubem Rosa, Hermes Lima; Djacír Menezes, Odilon C. Andrade, Rodrigues Vale, Oswaldo Aranha Bandeira de Melo e Luiz Delgado. To dos com uma única preocupação: estudar o "Direito Administrativo" em razão da realidade nacional. Não esquecendo também, pelo alto serviço prestado à cultura brasileira, o que iá realizou a "Fundação Getúlio Vargas", com a magnífica equipe comandada pelo professor Benedito Silva. A "Biblioteca de Administração Pública", reunindo autores nossos e estrangeiros, trouxe contribuição valiosíssima. Além disso, divulgando os seus "Cadernos de Administração Pública", tornou acessível o conhecimento prático do "Direito Administrativo", 
em tudo ąquilo quanto diz respeito ao serviço civil e ao problema do pessoal, ao municipalismo e aos problemas de organização técnica e racial.

Duas importantes publicações projetaram nossos estudiosos aqui dentro do Brasil e lá fora no estrangeiro: a Revista "Direito" e a "Revista de Direito Administrativo". A Revista "Direito" surgiu sob a direção e responsabilidade de dois imensos nomes: Clóvis Bevilaqua e Eduardo Espinola. Na "Seção" especializada de "Direito Administrativo" estavam Ruben Rosa, Mário Masagão, Manoel de Oliveira Franco Sobrinho e Rui Cirne Lima. A "Revista de Direito Administrativo", sob direção de Carlos Medeiros Silva e redação de A. Gonçalves de Oliveira e Vitor Nunes Leal, divulgando legislação, pareceres, jurisprudência e doutrina, iniciou a fase áurea do Direito Administrativo Brasileiro.

$$
\text { * * * }
$$

Estava assim justificado o otimismo do ilustre saudoso professor paulista. Depois de largo objetivo comentário assim escrevia Tito Prates da Fonseca: - "Vários outros escriłos particularizados têm, ultimamente, surgido, que aponto no corpo do livro. Com êles preciso apren. der a discutir. Espero que a seára continue, para firmeza da doutrina administrativa brasileira. E está continuando. Haja visto o excelente arrigo do professor Mancel de Oliveira Franco Sobrinho, sôbre a "Noção Social de Autarquia", publicado no Jornal do Comércio, de 5 de junho do corrente ano. Neste trabalho, examina espaçadamente o distinto professor da Universidade do Paraná, a noção e caracterização do serviço público". (DIREITO ADMINISTRATIVO - ed. 1939 - págs. XIV e XV). Em todos os Estados o interêsse era o mesmo. A literatura estrangeira começava a ser procurada com maior intensidade. Inclusive no Paraná também...

$$
\text { *** }
$$

Podem outros ainda merecidamente ser lembrados pela expressão marcante das suas contribuições intelectuais. Mostram o que é o "Direito Administrativo" no Brasil, o ponderável avanço conseguido em tão curto espaço de tempo. São nomes que também fazem história da nossa disciplina. Com estudos próprios de reconhecimento nacional: - AGUIAR DIAS, ALAIM DE ALMEIDA CARNEIRO, ALCINO DE PAULA SALAZAR, ALFREDO CECILIO LOPES, BILAC PINTO, LUCIO BITTENCOURT, CAIO TÁCITO, CARLOS MEDEIROS DA SILVA, CARLOS S. DE BARROS JUNIOR, CASTRO NUNES, DJACIR MENEZES, EDUARDO PINTO PESSOA, FERNANDO MENDES DE ALMEIDA FRANCISCO CAMPOS, A. GONÇALVES DE OLIVEIRA, HAROLDO VALADÃO, LA- 
FAYETTE PONDÉ, NOGUEIRA DE SÁ, ODILON BRAGA, ODILON ANDRADE, ONOFRE MENDES, OSWALDO BANDEIRA DE MELLO, SEABRA FAGUNDES, VICTOR NUNES LEAL, JOSÉ FREDERICO MARQUES, JOSÉ CRETTELA JUNIOR, CONTREIRAS DE CARVALHO, ANDRADE FURTADO, TAVARES DE LYRA FILHO.

Não fôsse o "Direito Administrativo", pela difícil posição dinâmica do Estado, tão complexo nas suas manifestações científicas, quem sabe houvesse provocado outras paixões. No entanto, o que já se escreveu e produziu, coloca o Brasil em margem de igualdade com outras nações mais afeitas aos sucessos da vida jurídica.

$$
* * *
$$

Com tendência de espírito para os estudos de direito público caminhar para o "Direito Administrativo" foi inclinação natural do professor Manoel de Oliveira Franco Sobrinho. Desde cedo, muito cedo ainda, porque ainda muito jovem, publicou a sua primeira tese, tese que defendeu no "Primeiro Congresso Jurídico Universitário do Brasil", realizado em 1936 na cidade de Salvador, Capital da Bahia. Como era de esperar a proposição Oliveira Franco obteve aceitação geral. Publicada depois, em modesta plaquete, trazia apresentação altamente honrosa. Apresentava o trabalho do então acadêmico o ConseIheiro Filinto Bastos, Diretor da Faculdade de Direito da Bahia, que o fazia com as seguintes palavras: - "A tése - CONCESSÃO DE SERVIÇOS PÚBLICOS EM DIREITO ADMINISTRATIVO - do distinto acadêmico Oliveira Franco Sobrinho, da Faculdade de Direito da Universidade do Paraná, evidencia grande capacidade de estudo e seguro critério na apreciação do assunto analisado". Dali para diante, lutando contra ambiente provinciano, outros estudos viriam para notabilizar o autor paranaense.

$$
\text { * * * }
$$

Não muito tempo depois, defendendo tése de Docente Livre na Faculdade de Direito da Universidade do Paraná, publicava "DO CONCEITO DO CONTRATO ADMINISTRATIVO", que pela originalidade' e fundamentos bibliográficos, recebia encômios de Temistocles Cavalcanti, Tito Prates da Fonseca, Ulisses Rodrigues e de Placido e Silva. Citado no estrangeiro e aqui no Brasil publicou outros dois trabalhos que marcaram profunda evolução no pensamento doutrinário: "OS SERVIÇOS DE UTILIDADE PÚBLICA" e "DESAPROPRIAÇÃO POR UTILIDADE PÚBLICA". Com intensa vocação para o estudo prático emitia pareceres e divulgava ensaios que tiveram a acolhida das "Revistas" especializadas. No "Arquivo Judiciário", como na "Revista dos Tribunais", publicou dois trabalhos interessantíssimos: NOÇÃO JURÍDICA DE AUTARQUIA (Vol. XLVII - Rio 1939) e o CONTRATO ADMINISTRATIVO, NOÇÃO E FUNDAMENTOS (Vol. CXXXIII - S. Paulo, 
1941). Na Revista "Direito" tornava público AVALIAÇÃO DE BENS e CAPITAL PARA EFEITO DE DESAPROPRIAÇÃO DAS ENTIDADES DELEGADAS DE SERVIÇO PÚBLICO (Vol. IX - Rio, 1941).

$* * *$

Consagrou-se o professor Manoel de Oliveira Franco Sobrinho publicando uma "monografia" de sucesso: AUTARQUIAS ADMINISTRATIVAS apresentada por Clóvis Beviláqua com as seguintes expressivas palavras: - "E' trabalho de mestre: seguro na doutrina, erudito e metódico. Não parece de um moço, e sim de umã inteligência vigorosa já amadurecida, e com individualidade firmada na meditação constante". O "Boletim do Ministério do Trabalho", divulgou êsse livro em todos os seus capítulos mais importantes, ressaltando na apresentação os méritos da enorme investigação realizada e das conclusões obtidas (ns. 50, 56 e 57 - Ano V-. Também a "Revista dos Tribunais" de S. Paulo e o "Arquivo Judiciário" do Rio de Janeiro transcreviam em números diferentes o trabalho do professor Oliveira Franco que se tornou assim clássico na nossa literatura iurídico-administrativa. Afirmo que está merecendo republicação...

$$
* * *
$$

Nas funções públicas que exerceu sempre assim se comportou: como um profundo estudioso do "Direito Administrativo". Advogado, professor e político, acredito que ainda não the houvesse sobrado tempo material para elaboração de obra definitiva. No entanto, ei-lo Deputado Federal, apresentando dois projetos-de-lei interessantíssimos: projeto "Regulando as Normas Gerais do Procedimento no Inquérito Administrativo" (n. 1.419/1956) e outro projeto "Regulando o Procedimento Normativo no Recurso Administrativo" (n. 1491/1956). Em ambos os projetos houve a preocupação da boa técnica administrativa. Justificando o primeiro dizia:"Há institutos do Direito Administrativo que não podem mais viver sòmente das praxes e dos costumes. Onde a necessidade da fixação harmoniosa das normas em sistema próprio sòmente podem facilitar a atividade jurídica do poder público". Na justificação do segundo esclarecia: "além da fixidez e clareza das regras administrativas, tôda codificação como sistema, é também método". Sempre acreditou nas vantagens da codificação administrativa.

$$
* * *
$$

A passagem do professor Manoel de Oliveira Franco Sobrinho pela Direção da Caixa Econômica Federal do Paraná deu-lhe oportunidade para comprovar sua atitude com respeito às vantagens da codificação administrativa. Anteriormente, sôbre a mesma temática, já havia publicado dois estudos definidores: PROCESSO E DIREITO 
ADMINISTRATIVO (Rev. da Fac. de Dir. da Universidade do Paraná - Ano II, n. 2 - 1954) e DA POSIÇÃO JURÍDICA DO DIREITO PRO' CESSUAL ADMINISTRATIVO (Rev. "Direito" - Vol. II - 1940). Ambos os trabalhos a!cançaram êxito. Mas o esforço na feitura do que chamou ORGANIZAÇÃO E SISTEMA DO PROCESSO ADMINISTRATIVO DA CAIXA ECONÔMICA FEDERAL DO PARANÁ resultou em maior êxito ainda. Em vigência a regulamentação Oliveira Franco produziu frutos bastante benéficos. "Nosso trabalho, - afirmava - objetiva o seguinte: coordenar os princípios administrativos em vigôr nos processos que transitam pela Caixa, uniformizando-os, simplificandoos, racionalizando-os. Era intenção do autor da regulamentação: ECONOMIA NO TEMPO E DE TEMPO, RAPIDEZ DE EXECUÇÃO E NA EXECUÇÃO, AUMENTO DE EFICIÊNCIA, MENOS DESPERDÍCIO E MAIOR REDUÇÃO NOS GASTOS.

\section{$* * *$}

Tenho em mãos outro trabalho que ficou quase esquecido. Trata-se da elaboração de lei que foi aprovada pela Assembléia Legislativa quando o professor Oliveira Franco Sobrinho ocupava o cargo de Secretário dos Negócios do Govêrno, no Paraná. Publicado em volume ganhou o título de CLASSIFICAÇÃO DE CARGOS E PLANO DE PAGAMENTO. Por efeito dessa lei ficou criado o Departamento Estadual do Serviço Público (DESP). Na exposição de motivos apresentada ao Governador do Estado, estava tôda uma experiência adquirida na prática administrativa e no estudo dos bons livros. Assim explicava, em têrmos claros, o professor Oliveira Franco:

- "A organização do serviço civil é condição jurídica da própria estabilidade da administração pública. As exceções legislativas e os favores governamentais criam o desajustamento funcional e a despadronização dos vencimentos, - dois imperativos imponderáveis da caducidade do mecanismo administrativo.

"O crescimento desproporcionado dos negócios público-administrativos, a complexidade de amplitude da máquina de administração, a necessidade do pessoal técnico especializado, do enquadramento das carreiras burocráticas, - obriga a um conhecimento imediato da realidade funcional.

"Administração é mecanismo orgânico. Organismo é composição de órgãos harmônicos. Sem função não se vitaliza o órgão. Mas, como inerente à própria função, no mesm: : sentido orgânico administrativo geral, está o agente da administração, - está o funcionário público.

"O estatuto, como tábua de lei, não é orgariização administrativa. Assinado pelo poder público, trata de caracterizar as possíveis relações jurídicas contratuais entre 
- Estado administrador e os agentes da administração. Não dá ordem ao serviço civil, não faz organização administrativa". (P. 13).

Atendendo à técnica administrałiva e à realidade da administração, procurava o professor Oliveira Franco dar sentido às exigências mais atuais no que dizia respeito às promoções, ao acesso, ao provimento, aos quadros, ao tempo de trabalho, ao enquadramento, à readaptação, ao plano de pagamento e vencimentos, - numa visão realista dos problemas de govêrno e de funcionalismo.

$$
* * *
$$

D'outra feita, ocupando a Secretaria do Interior e Justiça, também no Estado do Paraná, não esqueceu da sua condição de cultor estudioso do "Direito Administrativo". Ordenou e consolidou tôdas as leis peculiares aos interêsses municipais. Sua intenção era de orientar dentro da boa técnica dé conhecimento administrativo.

Assim pensava, como assim escreveu:

- "O município é fôrça imperativa da vida nacional. Sem o município, não haveria o Estado, nem a Federação. Quando o Brasil surgiu, como nação independente, o processo político assentou na base localista, afirmando condições próprias ao desenvolvimento econômico.

"O município paranaense, realizando obra de descentralização administrativa, no sentido do alargamento das fronteiras econômicas, contribuiu para o fortalecimento do processo democrático e para o esclarecimento da verdade política.

"Mesmo onde os regimes sejam unitários, no município está assente, pelos seus peculiares interêsses próprios, tôda a vida da nação, sua capacidade autonômica e seu poder de soberania. Nos regimes federados, maior a razão: o município se evidencia como fôrça de valor integrativo e de unidade política nacional".

No seu livro-tése já havia anteriormente doutrinado: "Não é possível Estado sem administração. Esta será assim o comêço de tôda atividade estatal. No exemplo da organização constitucional brasileira: o município está para o Estado federado como o Estado federado está para o Estado federal" (O PROBLEMA DA MUNICIPALIZAÇÃO DOS SERVIÇOS PÚBLICOS - pg. 65).

$$
* * *
$$

Examinando o mais recente trabalho do professor Manoel de Oliveira Franco Sobrinho, - depois de dois outros publicados por outros caminhos de ensinamento jurídico - AFIRMAÇÕES NA PRÁTICA DO 
DIREITO INTERNACIONAL E REFLEXÕES EM TÔRNO DO DIREITO INTERNACIONAL POLÍTICO - sòmente poderia repetir o que já disseram Clóvis Beviláqua, Filinto Bastos e Tito Prates da Fonseca. A obra do mestre está continuando: firmada na experiência a assentada na boa doutrina. Procurando ser verdadeiro, autêntico nas suas idéias, sóbrio nas expressões, não esquece nunca de apresentar conclusões através dos justos debates. Poderiamos bem dizer como Jean Cruet: "Se já não se pode governar pela fé, é necessário governar pela ciêni cia, e se a ficção, já não ilude ninguém, é necessário por uma última esperança na verdade". (A VIDA DO DIREITO - p. 20). Assim está fazendo o professor Oliveira Franco Sobrinho quando coloca sua conciência em defesa da verdade iurídica e das realidades da ciência jurídica.

$$
* * *
$$

Seu nôvo livro não é tão nôvo quanto poderia ser porque as verdades nem sempre são novas. Ensinando que a municipalização dos serviços públicos está em razão da nossa formação política e constitucional, não versa o professor Manoel de Oliveira Franco Sobrinho apenas questões teóricas. Péln contrário, procura o quanto pode, raciocinando com muita clareza lógica, os elementos fundamentais de geografia e história. Defende, com os mais valiosos argumentos, a posição do município e dos serviços municipalizáveis que the são essenciais e peculiares. Creio que êste livro - tentativa de sistematização de uma teoria jurídica de direito público-administrativo será de grande utilidade para os estudiosos de "Direito Adminishrativo", como para aqueles interessados na análise das instituições políticas modernas.

$$
* * *
$$

Estudar a posição do Estado em face da administração, já é por si só uma grande tarefa. Estudar o conceito de administração do ponto de vista das relações políticas, outra importante tarefa. Foi o que fez o professor Manoel de Oliveira Franco Sobrinho em vários trabaIhos sínteses de investigação social. Porque o social, para êle, não desconhece o político. Como o valor polííco não prescinde dos valores jurídicos. "Em todas as sociedades humanas importam os elementos integrativos", - é o que afirma. "No município está a origem de todos interêssés públicos", - é o que reafirma. Mas acompanhar o desenvolvimento do raciocínio temático, não é muito fácil para aqueles que não esiejam afeitos aos problemas de natureza pública.

$$
* * *
$$

A obrigação do prefaciador não será outra que apresentar em prefácio o trabalho que se lhe deu para analisar. Aqui, porém, não se faz necessário apresentação formal. O professor Manoel de Olivei- 
ra Franco Sobrinho, pelas inúmeras contribuições para o estudo e desenvolvimento do "Direito Administrativo", é nome bastante conhecido. Pertence à bibliografia de ilustres juristas estrangeiros. Ao acaso, cito dois: Enrique Sayaqués Laso (TRATADO DE DERECHO ADMINISTRATIVO - Montevidéu, 1953) e Benjamin Villeagas Balsavibaso DERECHO ADMINISTRATIVO - Buenos Aires, 1950). No Brasil, sua constância nas contribuições, tornaram-no autoridade na matéria. Felizmente, posso dizer, está continuando. Está continuando para firmeza da doutrina administrativa brasileira, como asseverou Tito Prates da Fonseca...

\section{$* * *$}

Não obstante seus estudos que podem ser considerados clássicos, pois a maioria dos autores que cita se mantêm dentro de escolas tradicionais, o professor Manoel de Oliveira Franco Sobrinho surge, neste como em outros livros, exteriorizando indisfarçável vocação renovadora e progressista. Não é de hoje que assim procede em seus escritos. Lembro discurso pronunciado em 1943, quando paraninfou a turma de bacharéis daquele ano, na Faculdade de Direito da Universidade do Paraná. Assim, já falava àquele tempo, para os moços:

"- Passamos por uma época angustiosa onde se desencontram as doutrinas filosóficas, desharmonizam os sistemas políticos, chocam-se as soluções econômicas. Não falando nos embates de ordem social que consomem as energias mais ativas da sociedade moderna.

"O Estado torna em abstração indispensável. A realidade porém, está no povo, nas necessidades do povo, na consciência do povo, no vigôr do povo, no indivíduo isolado da massa e que compõe o povo. A soberania e todo poder assenta na coletividade, contrariando a tão falada superioridade político-jurídica do Estado, na reação contra o individualismo jurídico-político do século dezoito.

"O conceito de evolução integraliza todos os fenômenos, funde todas as teorias, destrói os sistemas filosóficos que pretendiam fundamentar o con'hecimento dos proble. mas da vida, na distinção jurídica do homem e sua nature. za animal. Ninguém mais, hoje em dia, poderá desagregar o homem jurídico, do moral ou do político. O homem como unidade e totalidade, - como unidade passível de direitos e como totalidade fonte de todo o poder.

"A sociedade é fato incontéste e permanente. Não obstante as indagações do relativismo jurídico, a vida social demonstra que não podemos arranciar o direito das suas raízes: a lei natural e a lei eterna. O direito será precisamente a inserção do indivíduo na sociedade, uma ex- 
pressão de associação onde a unidade e a totalidade não impeçam o evolver normal da personalidade" (PALAVRA AOS MOÇOS - p. 12).

Bastavam, estou certo, estas poucas linhas, para prefácio de todos os trabalhos que pensa ainda publicar o professor Oliveira Franco. Sua atitude está clara na fidelidade do seu pensamento. Sua posição tomada não mudou nestes vinte anos. Continua o mesmo trabalhador intelectual. "Seguro na doutrina e com individualidade firmada na meditação consłanłe", como dele disse Clóvis Beviláqua. No "Direito Administrativo" tem que ser assim: não basta analisar os fatos na evolução do processo político, mas entendê-los face a realidade que é do homem, é da sociedade e é do Estado.

$$
* * *
$$

Conceituando o município e o problema da descentralização, penetrando na ação do Estado face à administração, opinando entre centralização e descentralização, analisando a autonomia e a tutela administrativa procurando os fundamentos econômicos dos serviços de interêsse público, optando entre estatização e municipalização, delimitando a ação do poder municipal e marcando a extensão do "Direito Administrativo", desenvolve o professor Manoel de Oliveira Franco Sobrinho argumentos que são decisivos para a defesa da integração no município de todos aqueles serviços que the "são essenciais e peculiares". As Constituições brasileiras, como a legislação constitucional de outras nações, sempre determinaram respeito pela aułonomia municipal. Mas condições econômicas resultantes de fatores políticos conhecidos, têm impedido que os municípios representem o papel relevante que deles se espera.

$$
* * *
$$

E' altamente valiosa a contribuição do professor Manoel de Oliveira Franco Sobrinho para a compreensão do problema. Enxergando o Direito Administrativo como ciência, técnica, mecânica funcional e ordenamento jurídico, junta em rápidas sinteses os elementos necessários indispensáveis à formulação da verdade constitucional. Procura sempre não propôr fáceis soluções. O que procura, com argumentos expositivos, é juntar os pedaços esparsos de uma estrutura que se desagrega em prejuízo de unidade social. Se o município faz unidade, como unidade deve ser entendido. Se a legislação é falha, revisemos a legislação. Não existem motivos para controvérsias insanáveis. Este parece ser, acredito mesmo que seja, o pensamento e a intenção, a atuação intelectual e idéia motriz, do ilustre professor Manoel de Oliveira Franco Sobrinho. Não há ponto de partida mais certo. 